\section{Penaksiran Generalized Method of Moments dengan Penggunaan Metode Marquardt-Levenberg}

\author{
Nurul Mukhlisah Abdal ${ }^{1}$, Wahyudin Nur ${ }^{2}$ \\ Ainun Mawaddah Abdal ${ }^{3}$ \\ ${ }^{1}$ Universitas Negeri Makassar \\ ${ }^{2}$ Universitas Sulawesi Barat \\ 3 Universitas Hasanuddin \\ Email:nm.abdal@unm.ac.id ${ }^{1}$
}

Abstract. Generalized Method of Moments is a method for estimating parameters using sample moments. GMM is used by the researcher particularly in economics to determine econometrical models which their distribution function is hardly known. Not only for economics, but GMM also is useful for agriculture, transportation, health care, etc. Research methodology for this article is review of literature. This article describes the combination of GMM and Marquardt-Levenberg algorithm along with the example of its use.

Keywords: Generalized Method of Moments, GMM, Marquardt-Levenberg algorithm, parameter estimation

\section{INDONESIAN JOURNAL OF FUNDAMENTAL SCIENCES \\ (IJFS)}

E-ISSN: 2621-6728

P-ISSN: 2621-671x

Submitted: January, $9^{\text {th }} 2020$

Accepted: March, $22^{\text {nd }} 2020$

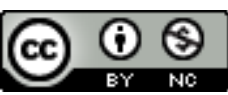

This work is licensed under a Creative Commons Attribution-NonCommercial 4.0 International License 


\section{PENDAHULUAN}

Generalized Method of Moments (GMM) merupakan salah satu metode yang dapat digunakan untuk melakukan penaksiran parameter, selain Maximum Likelihood Estimator (MLE) dan Method of Moments (MM). GMM pertama kali dikembangkan oleh Hansen (1982). GMM adalah metode penaksiran yang menggunakan model agar menghindari asumsi yang kadang tidak diinginkan atau tidak dibutuhkan, yaitu salah satunya adalah menetapkan distribusi khusus untuk residual (Ullah dkk., 2018; Salawu, 2017; Dufour dkk., 2017). Pada tabel di bawah ini akan diperlihatkan kelemahankelemahan dari MLE dan MM jika dibandingkan dengan GMM.

Tabel 1. Kelemahan Metode Panaksir Parameter

\begin{tabular}{cl}
\hline Metode & \multicolumn{1}{c}{ Kelemahan } \\
\hline MLE & Kepekaan sifat statistik terhadap asumsi distribusi. Sifat statistik yang \\
& sesuai dengan MLE hanya akan diperoleh jika distribusi yang dipilih tepat. \\
& Sebaliknya jika distribusi yang tidak tepat yang dipilih, akan terjadi \\
& kesalahan dalam pengambilan kesimpulan. Akan tetapi, untuk memperoleh \\
& perincian distribusi peluang data yang lengkap dalam teori ekonomi jarang \\
& terjadi. Satu-satunya jalan adalah dengan memilih distribusi sebarang. \\
& Meskipun demikian, kalau tebakan distribusinya tidak sesuai dengan yang \\
& sebenarnya, hasil penaksiran tersebut tidaklah optimal. Akibatnya dapat \\
& memperburuk keadaan dengan penarikan kesimpulan yang bias. \\
\hline & Masalah komputasi. Komputasi untuk memperoleh parameter pada \\
beberapa model seperti exchange rate (nilai tukar mata uang), investment \\
(investasi) dan macroeconomic forecasts (peramalan makroekonomi) \\
sangatlah berat. Ada dua tipe masalah komputasi yang sering muncul. \\
Masalah pertama adalah apabila model ekonomi telah sesuai dengan \\
distribusi peluang gabungan data yang dipilih, tetapi selanjutnya terjadi \\
kesulitan dalam perhitungan numerik untuk nilai fungsi likelihood. Nilai \\
likelihood tersebut sangat sulit diperoleh dengan teknologi komputasi yang \\
ada pada saat ini. Masalah kedua adalah model ekonomi hanya melibatkan \\
beberapa aspek distribusi peluang. Penyelesaian untuk informasi yang lebih \\
terinci membutuhkan banyak parameter tambahan yang juga harus \\
ditaksir. Sehingga menambah beban perhitungan. \\
Prinsip utama MM adalah menentukan momen populasi melalui \\
pendekatan momen sampel yang bersesuaian. Penggunaan MM \\
mengharuskan jumlah momen (r) dan jumlah parameter (a) yang diketahui \\
sama besarnya. Sehingga, apa yang akan terjadi jika jumlah momen yang \\
diketahui lebih besar daripada jumlah parameter? Jika hanya menggunakan \\
sebagian dari yang diketahui, belum tentu dapat memenuhi momen yang \\
lain yang tidak digunakan. Sehingga ada beberapa informasi dari data yang \\
tidak digunakan.
\end{tabular}


Generalized Method of Moments (GMM) tidak memerlukan fungsi likelihood yang terperinci untuk menarik kesimpulan sehingga dapat meringankan beban dalam penghitungan (Hass dkk., 2016; Wang dkk., 2018). GMM juga dapat menaksir parameter ketika banyaknya momen lebih besar atau sama dengan banyaknya parameter. Dasar dari penaksiran parameter pada GMM adalah himpunan moment conditions (syarat momen) populasi yang diperoleh dari asumsi model ekonometri. Oleh karena itu, GMM bekerja dengan meminimumkan fungsi objektif untuk menemukan parameter taksiran. Hal inilah yang melatarbelakangi penulis untuk meneliti GMM.

Berdasarkan uraian di atas, untuk meminimumkan fungsi objektif GMM, digunakan Gradient Method (metode gradien). Fungsi objektif pada GMM berupa $Q=$ g'W $W_{T}$ yang akan dibahas lebih lanjut pada bagian selanjutnya. Karena berhubungan dengan meminimumkan suatu model, metode gradienlah yang kemudian selanjutnya menjadi alat. Secara umum, metode gradien dapat dituliskan dalam bentuk

$$
\beta^{(j+1)}=\beta^{(j)}-t_{n} \cdot p_{n} \cdot \gamma_{n}
$$

dengan $t_{n}$ adalah step, $p_{n}$ adalah matriks positif definit, dan $\gamma_{n}$ adalah gradien fungsi objektif. Perbedaan pada masing masing metode gradien terletak pada matriks positif definit yang digunakan. Metode iterasi yang akan digunakan dalam tulisan ini adalah Metode Marquardt-Levenberg.

Penelitian sebelumnya telah menunjukkan bagaimana penggunaan GMM yang meminimalkan fungsi objektif dengan Algoritma Nelder-Mead (dalam matlab dipanggil dengan sintax "fminsearch"). Akan tetapi, algoritma tersebut tidak cocok digunakan untuk meminimumkan fungsi yang berhubungan dengan menjumlahkan kuadrat error. Oleh karena itu, penulis merasa perlu memperbaiki dengan menggantinya menggunakan Metode Marquardt-Levenberg.

\section{KAJIAN PUSTAKA}

\section{Generalized Method of Moments (GMM)}

Hansen (1982) memperkenalkan GMM, metode yang sangat berguna yang dapat digunakan dalam ekonometrika dan statistika untuk menaksir parameter dari data yang diberikan oleh sebuah model. Tidak hanya digunakan dalam bidang ekonomi dan statistika, GMM kemudian mulai digunakan dalam beberapa bidang lainnya. Pengembangan GMM dalam bidang lainnya oleh Hall (2005), GMM mengembangkan Method of Moments dengan dua cara, yaitu

1. GMM memproses suatu kasus yang memiliki dua atau lebih syarat momen yang mengandung informasi mengenai parameter yang tidak diketahui. GMM mampu mengerjakan penaksiran dan penarikan kesimpulan dalam sistem yang terdiri dari $r$ persamaan dan a parameter yang tidak diketahui, dimana $a \leq r$.

2. GMM juga dapat menggunakan data selain data sampel digunakan untuk menaksir parameter. GMM memanfaatkan Law of Large Numbers dan teorema limit pusat untuk menentukan keteraturan syarat dari banyak syarat momen. 
Kedua perubahan tersebut menghasilkan penaksir yang dapat diaplikasikan dengan luas. Prosedur dalam GMM adalah dengan meminimumkan criterion function (fungsi kriteria) sedemikian sehingga

$$
Q\left(v ; x_{T} ; x_{T-1}, \cdots, x_{1}\right) \equiv g^{\prime} W g
$$

di mana $W$ adalah matriks pembobot simetri positif definit. Matriks $W$ pada GMM berguna untuk menggambarkan seberapa pentingnya hubungan antara masing-masing persamaan. Contohnya, semakin besar nilai entri $(2,1)$ pada matriks $W$, maka makin kuat hubungan antara momen ke-dua dan momen ke-satu.

1) Definisi 1. Andaikan $w_{t}(I \times 1)$ adalah vektor variabel yang terobservasi pada waktu $t$, $\theta(a \times 1)$ menyatakan vektor koefsien yang tidak diketahui, dan $h\left(\theta, w_{t}\right)$ adalah vektor nilai fungsi, $h:\left(\mathbb{R}^{a} \times \mathbb{R}^{h}\right) \rightarrow \mathbb{R}^{r}$. Karena $w_{t}$ adalah variabel acak, maka juga berlaku untuk $h\left(\theta, w_{t}\right)$. Misalkan $\theta_{0}$ menyatakan nilai sebenarnya dari $\theta$, dan andaikan nilai sebenarnya ini dicirikan oleh orthogonality conditions (syarat ortogonal) atau moment conditions (syarat momen), yang mana disimbolkan sebagai

$$
E\left[h\left(\theta_{0}, w_{t}\right)\right]=0
$$

Misalkan $\wp_{T}(T l \times 1)=\left(w_{T}^{\prime}, w^{\prime}{ }_{T-1}, \cdots, w_{1}^{\prime}\right)$ adalah vektor yang mengandung semua hasil pengamatan pada sampel yang berukuran T. $g\left(\theta, \wp_{T}\right)$ menyatakan rata-rata sampel $h\left(\theta, w_{t}\right)$ yang berukuran $(r \times 1)$, yaitu

$$
g\left(\theta, \wp_{T}\right) \equiv \frac{1}{T} \sum_{t=1}^{T} h\left(\theta, w_{t}\right)
$$

Poin penting dalam GMM adalah memilih momen sampel $g\left(\theta, \wp_{T}\right)$ sedekat mungkin dengan momen populasi. Agar selisih antara momen sampel dan momen populasi

mendekati nol. Caranya adalah nilai $\theta$ taksiran yang diperoleh dari GMM $(\hat{\theta})$ harus meminimumkan nilai

$$
Q\left(\theta, \wp_{T}\right)=\left[g\left(\theta, \wp_{T}\right)\right]^{\prime} W_{T}\left[g\left(\theta, \wp_{T}\right)\right]
$$

di mana $W_{T}(r \times r)$ adalah matriks pembobot simetri positif definit. Terlihat pada persamaan (5) bahwa nilai $Q\left(\theta, \wp_{T}\right) \geq 0$. Nilai $Q\left(\theta, \wp_{T}\right)=0$ kan terpenuhi jika dan hanya jika $g\left(\theta, \wp_{T}\right)=0$.

Oleh karena itu, penaksiran $\theta_{0}$ dengan GMM dapat disimpulkan sebagai berikut

$$
\hat{\theta}=\underset{\theta}{\arg \min } Q\left(\theta, \wp_{T}\right)
$$

\section{Matriks Pembobot Optimal}

Andaikan ketika mengevaluasi $\theta_{0}$, proses $\left\{h\left(\theta_{0}, w_{t}\right)\right\}_{t=-\infty}^{\infty}$ adalah proses stasioner kuat dan tidak berkorelasi antar deret dengan mean nol dan matriks autokovarians ke- $v$ dinyatakan oleh 


$$
\Gamma_{v}=E\left\{\left[h\left(\theta_{0}, w_{t}\right)\right]\left[h\left(\theta_{0}, w_{t-v}\right)\right]^{\prime}\right\}
$$

Asumsikan matriks autokovarians tersebut memiliki sifat absolutely summable (dapat dijumlahkan secara mutlak), didefinisikan sebagai berikut

$$
S \equiv \sum_{v=-\infty}^{\infty} \Gamma_{v}
$$

Karena kesulitan untuk menjangkau semua titik yang ada pada populasi, sehingga masing-masing titik diwakilkan dengan rata-rata titik-titik tersebut. Dalam Hamilton ${ }^{[4]}$ ditunjukkan sebagai berikut

$$
S=\lim _{T \rightarrow \infty} T \cdot E\left\{\left[g\left(\theta_{0} ; \wp_{T}\right)\right]\left[g\left(\theta_{0} ; \wp_{T}\right)\right]^{\prime}\right\}
$$

Berdasarkan persamaan (5), $S$ untuk vektor proses $\left\{h\left(\theta_{0}, w_{t}\right)\right\}_{t=-\infty}^{\infty}$ yang serially uncorrelated (tidak berkorelasi antar deret) dapat diperoleh dengan

$$
S^{*}=\frac{1}{T} \sum_{t=1}^{T}\left[h\left(\theta_{0}, w_{t}\right)\right]\left[h\left(\theta_{0}, w_{t}\right)\right]^{\prime}
$$

Karena pada persamaan (9) nilai $\theta_{0}$ harus diketahui terlebih dahulu, sehingga $S^{*}$ dapat ditaksir dengan

$$
\hat{S}_{T} \equiv \frac{1}{T} \sum_{t=1}^{T}\left[h\left(\hat{\theta}_{T}, w_{t}\right)\right]\left[h\left(\hat{\theta}_{T}, w_{t}\right)\right]^{\prime} \stackrel{p}{\longrightarrow} S
$$

Penaksiran dengan GMM menggunakan alur yang berputar. Sebelum bisa melakukan penaksiran terhadap $\theta$, matriks $S$ harus diketahui terlebih dahulu agar dapat meminimumkan fungsi objektif $Q$. Untuk menaksir matriks $S, \theta$ harus diketahui untuk disubtitusikan ke persamaan (10). Oleh karena itu, prosedur penaksiran GMM dapat dilakukan dengan cara berikut:

1) Memilih $W=I_{r}$ untuk memperoleh nilai awal parameter $\hat{\theta}_{T}^{(0)}$ pada persamaan (5).

2) Hasil taksiran $\theta$ yang berupa $\hat{\theta}_{T}^{(0)}$ kemudian disubtitusikan ke persamaan (10), sehingga diperoleh $\hat{S}_{T}^{(0)}$ yang merupakan nilai awal $\hat{S}_{T}$.

3) Persamaan (5) diminimumkan dengan mensubtitusikan $\left(\hat{S}_{T}^{(0)}\right)^{-1}$ sebagai $W_{T}$ untuk memperoleh $\hat{\theta}_{T}^{(1)}$

Proses iterasi di atas dapat dilakukan berkali-kali hingga diperoleh $\hat{\theta}_{T}^{(j)} \cong \hat{\theta}_{T}^{(j+1)}$. Semakin banyak iterasi, maka hasil penaksiran yang diberikan lebih baik sehubungan dengan batas ukuran data dan nilai awal matriks pembobot $W_{T}$. Akan tetapi, proses yang serially uncorrelated jarang terjadi dalam kehidupan nyata, sehingga dalam tulisan ini digunakan matriks vektor proses $\left\{h\left(\theta_{0}, w_{t}\right)\right\}_{t=-\infty}^{\infty}$ yang berkorelasi antar deret. 
Dengan kata lain momen yang satu dengan momen yang lain saling memiliki hubungan. Oleh karena itu, digunakan penaksiran S oleh Newey-West ${ }^{[13]}$, yaitu

$$
\begin{gathered}
\hat{S}_{T}=\hat{\Gamma}_{0, T}+\sum_{v=1}^{q}\left\{1-\left[\frac{v}{q+1}\right]\right\}\left(\hat{\Gamma}_{v, T}+\hat{\Gamma}_{v, T}^{\prime}\right) \\
\hat{\Gamma}_{v, T}=\frac{1}{T} \sum_{t=v+1}^{T}\left[h\left(\hat{\theta}, w_{t}\right)\right]\left[h\left(\hat{\theta}, w_{t-v}\right)\right]^{\prime}
\end{gathered}
$$

dan $q$ adalah autokovarians yang digunakan.

Dengan demikian, persamaan (5) dapat diubah menjadi

$$
Q\left(\theta, \wp_{T}\right)=\left[g\left(\theta, \wp_{T}\right)\right]^{\prime} S_{T}^{-1}\left[g\left(\theta, \wp_{T}\right)\right]
$$

\section{Metode Marquardt-Levenberg}

Metode Marquardt-Levenberg merupakan pengembangan antara metode GaussNewton dan metode Steepest Descent.

- Ketika solusi jauh dari yang seharusnya, iterasi Marquardt-Levenberg akan berperan sebagai iterasi Steepest Descent, yang bersifat lambat, tapi menjamin kekonvergenan.

- Ketika solusi sudah dekat dengan solusi yang sebenarnya, iterasi MarquardtLevenberg akan berperan sebagai iterasi Gauss-Newton: bekerja dengan cepat.

Dengan menggunakan metode least square sebagai landasan Syamsuddin (2005), digunakan

$$
\min _{\theta} K(\theta)=(y-f(X, \theta))^{\prime}(y-f(X, \theta))
$$

Syarat perlu untuk meminimumkan adalah

$$
\begin{aligned}
\frac{\partial K(\theta)}{\partial \theta^{\prime}}= & {\left[\frac{\partial f(X, \theta)}{\partial \theta^{\prime}}\right]^{\prime}(y-f(X, \theta)) } \\
& =[D(\theta)]^{\prime}(y-f(X, \theta)) \\
& =0 \\
& D\left(\theta^{(j)}\right)=\frac{\partial f(X, \theta)}{\partial \theta^{\prime}}
\end{aligned}
$$

Sehingga syarat perlu untuk persamaan (16) adalah

$$
[D(\theta)]^{\prime}(y-f(X, \theta))=0
$$


Algoritma menggunakan iterasi Marquardt-Levenberg dapat dilakukan dengan rumus berikut (Lee, 2010) yaitu:

$$
\theta^{(j+1)}=\theta^{(j)}-\left.t_{j}\left[D\left(\theta^{(j)}\right)^{\prime} D\left(\theta^{(j)}\right)+\lambda I_{a}\right]^{-1} \frac{\partial K}{\partial \theta}\right|_{\theta^{(j)}}
$$

di mana $t_{j}$ adalah adalah panjang langkah, $\lambda$ adalah parameter damping, serta

$$
D\left(\theta^{(j)}\right)=\frac{\partial f(X, \theta)}{\partial \theta^{\prime}}
$$

Dalam hal ini, digunakan $\lambda \geq 0$. Parameter damping mengakibatkan

1. Untuk setiap $\lambda>0$, matriks koefisien pada persamaan (20) bersifat definit positif dan menjamin bahwa step, yang mana step $=\theta^{(j+1)}-\theta^{(j)}$, merupakan descent direction (berada pada jalur yang tepat).

2. Untuk nilai $\lambda$ yang besar, diperoleh

$$
\text { step } \cong-\frac{1}{\lambda} \frac{\partial S}{\partial \theta}
$$

yaitu merupakan satu langkah kecil untuk mengawali iterasi, ketika iterasi saat ini masih sangat jauh dari solusi.

3. Untuk nilai $\lambda$ yang sangat kecil merupakan langkah yang baik pada akhir iterasi, pada saat parameter taksiran sudah mendekati nilai parameter sebenarnya.

Kriteria penghentian iterasi pada metode Marquardt-Levenberg (Lee, 2010) berdasarkan pada kondisi bahwa di titik $\quad \theta^{(j+1)}$ terjadi $\left.\frac{\partial K}{\partial \theta}\right|_{\theta^{(j+1)}}=0$, sehingga dapat digunakan syarat

1.

$$
\left\|\frac{\partial K}{\partial \theta}\right\|_{\infty} \leq \epsilon_{1}
$$

dengan $\epsilon_{1}$ adalah bilangan positif kecil yang dipilih.

2.

$$
\left\|\theta^{(j+1)}-\theta^{(j)}\right\| \leq \epsilon_{2}\left(\left\|\theta^{(j)}+\epsilon_{2}\right\|\right)
$$

dengan $\epsilon_{2}$ adalah bilangan positif kecil yang dipilih.

3. $j \leq j_{\max }$ besarnya $j_{\max }$ dipilih.

Aplikasi penggunaan Metode Marquardt-Levenberg dapat dilihat pada

\section{HASIL DAN PEMBAHASAN}

GMM bekerja dengan meminimumkan fungsi Q, seperti yang terlihat di bawah ini

$$
\min _{\theta} Q\left(\theta, \wp_{T}\right)=\left[g\left(\theta, \wp_{T}\right)\right]^{\prime} S_{T}^{-1}\left[g\left(\theta, \wp_{T}\right)\right]
$$

sehingga first order condition untuk nilai minimum fungsi objektif adalah 


$$
\begin{array}{r}
\frac{\partial Q\left(\theta, \wp_{T}\right)}{\partial \theta^{\prime}}=\frac{\partial}{\partial \theta^{\prime}}\left\{\left[g\left(\theta, \wp_{T}\right)\right]^{\prime} S_{T}^{-1}\left[g\left(\theta, \wp_{T}\right)\right]\right\} \\
0=\left[\frac{\partial\left[g\left(\theta, \wp_{T}\right)\right]}{\partial \theta^{\prime}}\right]^{\prime} S_{T}^{-1}\left[g\left(\theta, \wp_{T}\right)\right]
\end{array}
$$

di mana $\frac{\partial\left[g\left(\theta_{1} \wp_{T}\right)\right]}{\partial \theta^{\prime}}$ adalah matriks dengan sebanyak a kolom dan $r$ baris yang dapat dituliskan sebagai berikut

$$
\left.\begin{array}{cccc}
Z\left(\theta_{T}\right)=\frac{\partial\left[g\left(\theta, \wp_{T}\right)\right]}{\partial \theta^{\prime}} \\
\frac{\frac{\partial\left[g_{1}\left(\theta, \wp_{T}\right)\right]}{\partial \theta_{1}^{\prime}}}{\frac{\partial\left[g_{2}\left(\theta, \wp_{T}\right)\right]}{\partial \theta_{1}^{\prime}}} & \frac{\partial\left[g_{1}\left(\theta, \wp_{T}\right)\right]}{\partial \theta_{2}^{\prime}} & \cdots & \frac{\partial\left[g_{1}\left(\theta, \wp_{T}\right)\right]}{\left.\left.\partial \theta_{T}^{\prime}\right)\right]} \\
\vdots & \cdots & \frac{\partial\left[g_{2}\left(\theta, \wp_{T}\right)\right]}{\partial \theta_{a}^{\prime}} \\
\vdots & \ddots & \vdots \\
\frac{\partial\left[g_{r}\left(\theta, \wp_{T}\right)\right]}{\partial \theta_{1}^{\prime}} & \frac{\partial\left[g_{r}\left(\theta, \wp_{T}\right)\right]}{\partial \theta_{2}^{\prime}} & \cdots & \frac{\partial\left[g_{r}\left(\theta, \wp_{T}\right)\right]}{\partial \theta_{a}^{\prime}}
\end{array}\right]
$$

Dengan mensubtitusikan persamaan (26) dan (28) pada persamaan (20), diperoleh metode penaksiran GMM dengan penggunaan Metode Marquardt-Levenberg adalah

$$
\theta^{(j+1)}=\theta^{(j)}-\left.t_{j}\left[Z\left(\theta^{(j)}\right)^{\prime} S_{T}^{-1} Z\left(\theta^{(j)}\right)+\lambda I_{a}\right]^{-1} \frac{\partial Q}{\partial \theta}\right|_{\theta^{(j)}}
$$

Contoh berikut digunakan untuk menerapkan GMM dengan menggunakan Algoritma Marquardt-Levenberg sebagai alat untuk meminimumkan persamaan (24). Dengan menggunakan data yang dibangkitkan secara acak menggunakan MATLAB, lalu diaplikasikan ke dalam model Cox-Ingersoll-Ross (CIR), yaitu

$$
d r_{t}=\left(\alpha+\beta r_{t}\right) d t+\sigma \sqrt{r_{t}} d M_{t}
$$

$M_{t}$ adalah proses Wiener dan $\alpha, \beta$, dan $\sigma$ adalah parameter yang akan ditaksir. Dalam Kladivko[5] (2010) diperoleh fungsi momen untuk model CIR sebagai berikut,

Oleh karena itu, diperoleh syarat momen

$$
h\left(\theta_{0}, w_{t}\right)=\left[\begin{array}{c}
\varepsilon_{t+1} \\
\varepsilon_{t+1} r_{t} \\
\varepsilon_{t+1}^{2}-\sigma^{2} r_{t} \\
\left(\varepsilon_{t+1}^{2}-\sigma^{2} r_{t}\right) r_{t}
\end{array}\right]
$$

$$
\begin{gathered}
g\left(\theta, \wp_{T}\right)=E\left[h\left(\theta_{0}, w_{t}\right)\right]=0 \\
E\left[\begin{array}{c}
\varepsilon_{t+1} \\
\varepsilon_{t+1} r_{t} \\
\varepsilon_{t+1}^{2}-\sigma^{2} r_{t} \\
\left(\varepsilon_{t+1}^{2}-\sigma^{2} r_{t}\right) r_{t}
\end{array}\right]=0
\end{gathered}
$$

Cara kerja GMM adalah dengan memilih parameter yang paling cocok untuk syarat momen pada persamaan (31). Dengan menggunakan persamaan (33) sebagai syarat momen, diperoleh hasil simulasi seperti yang terlihat pada tabel II 
Table 2. Hasil Simulasi GMM dengan Penggunaan Algoritma Marquardt-Levenberg

\section{GMM -Marquardt-Levenberg}

\begin{tabular}{lcccc}
\hline $\begin{array}{l}\text { Parameter } \\
\text { estimasi }\end{array}$ & $\hat{\theta}=\left[\begin{array}{c}0.0086 \\
-0.0730 \\
0.0026\end{array}\right]$ \\
\hline $\begin{array}{l}\text { Matriks } \\
\text { pembobot }\end{array}$ & $\widehat{W}$ & & \\
& $=1.0 e+12$ & & \\
& {$\left[\begin{array}{cccc}0.000001 & -0.000012 & 0.000038 & -0.000536 \\
-0.000012 & 0.000142 & -0.000515 & 0.007365 \\
0.000038 & -0.000515 & 0.013706 & -0.154130 \\
-0.000536 & 0.007365 & -0.154130 & 1.833757\end{array}\right]$} \\
\hline $\begin{array}{c}\text { Nilai minimum } \\
\text { yang diperoleh }\end{array}$ & $Q=0.001987960647664$ & \\
\hline
\end{tabular}

Terlihat dalam Tabel 2, bahwa nilai Q paling minimum yang dapat diperoleh adalah 0.001987960647664. Semakin kecil nilai $Q$ yang diperoleh semakin baik parameter taksiran. Di mana parameter taksiran yang diperoleh, adalah $(\hat{\alpha}, \hat{\beta}, \hat{\sigma})=$ $(0.0086,-0.0730,0.0026)$. Berbanding terbalik dengan nilai $Q$, semakin besar $\widehat{W}$ yang diperoleh, akan semakin baik penaksiran parameter tersebut. Hal ini disebabkan oleh matriks pembobot $\widehat{W}$ tak lain adalah invers dari matriks varians-kovarians dari fungsi momen yang mana telah diketahui sebelumnya bahwa semakin kecil nilai entri-entri matriks varians-kovarians yang dimiliki, maka makin bagus data tersebut.

\section{KESIMPULAN}

Penelitian ini dimaksudkan sebagai usaha untuk memahami dan menjelaskan metode penaksiran parameter GMM serta penggabungannya dengan Metode MarquardtLevenberg. Selain dengan Metode Marquardt-Levenberg, GMM dapat digabungkan dengan algoritma yang dapat meminimumkan lainnya. Contohnya Algoritma Quadratic Hill Climbing, Algoritma Gauss Newton, dan lain-lain. Selain itu, pemilihan nilai awal juga sangat mempengaruhi GMM- Marquardt-Levenberg. Pemilihan nilai awal yang baik dapat menuntun menuju ke hasil yang baik dan juga meringankan proses komputasi.

\section{UCAPAN TERIMA KASIH}

Penulis ingin mengucapkan terima kasih kepada pihak-pihak yang telah membantu penulis selama penulisan artikel ini. Kepada Bapak Syamsuddin yang telah membantu penulis dalam memilihkan topik dan menuntun penulis mulai dalam pemahaman materi hingga artikel ini selesai.

\section{DAFTAR PUSTAKA}

Dufour, J. M., Trognon, A., \& Tuvaandorj, P. (2017). Invariant tests based on Mestimators, estimating functions, and the generalized method of moments. Econometric Reviews, 36(1-3), 182-204. 
Hall, A. R. Generalized Method of Moments. (2005). Advanced Texts in Econometrics. Oxford: Oxford University Press.

Hansen, L. P. (1982). Large Sample Properties of Generalized Method of Moments Estimators. Econometrica, 50 (4), 1029-1054.

Hass, Z., Levine, M., Sands, L. P., Ting, J., \& Xu, H. (2016). The modeling of medical expenditure data from a longitudinal survey using the generalized method of moments (GMM) approach. Statistics in medicine, 35(15), 2652-2664.

Lee, M. J. (2010). Micro-Econometrics. Method of Moments and Limited Dependent Variables. 2nd ed. Springer: London.

Salawu, M. K. (2017). Factors influencing auditor independence among listed companies in Nigeria: Generalized method of moments (GMM) approach. International Journal of Economics and Finance, 9(8), 191.

Syamsuddin. (2015). Teori Ekonometrika. Penerbit ITB: Bandung

Ullah, S., Akhtar, P., \& Zaefarian, G. (2018). Dealing with endogeneity bias: The generalized method of moments (GMM) for panel data. Industrial Marketing Management, 71, 69-78.

Wang, J., Zhang, L., \& Feng, Z. (2018). Allometric equations for the aboveground biomass of five tree species in China using the generalized method of moments. The Forestry Chronicle, 94(3), 214-220. 